\title{
METABOLIC EFFECTS OF THE VERY-LOW- CARBOHYDRATE DIETS: MISUNDERSTOOD "VILLAINS" OF HUMAN METABOLISM
}

\author{
Anssi H. Manninen
}

Advanced Research Press, Inc., New York, USA: Address correspondence to: sportsnutrition@luukku.com

Received June 22, 2004/Accepted December 10, 2004/Published (online)

\begin{abstract}
During very low carbohydrate intake, the regulated and controlled production of ketone bodies causes a harmless physiological state known as dietary ketosis. Ketone bodies flow from the liver to extra-hepatic tissues (e.g., brain) for use as a fuel; this spares glucose metabolism via a mechanism similar to the sparing of glucose by oxidation of fatty acids as an alternative fuel. In comparison with glucose, the ketone bodies are actually a very good respiratory fuel. Indeed, there is no clear requirement for dietary carbohydrates for human adults. Interestingly, the effects of ketone body metabolism suggest that mild ketosis may offer therapeutic potential in a variety of different common and rare disease states. Also, the recent landmark study showed that a very-lowcarbohydrate diet resulted in a significant reduction in fat mass and a concomitant increase in lean body mass in normal-weight men. Contrary to popular belief, insulin is not needed for glucose uptake and utilization in man. Finally, both muscle fat and carbohydrate burn in an amino acid flame. Journal of the International Society of Sports Nutrition. 1(2):7-11, 2004.
\end{abstract}

Key Words: low-carbohydrate diets, ketogenic diets, ketogenesis, ketosis, diabetic ketoacidosis, ketone bodies, gluconeogenesis, insulin, glucagon, carbohydrate recommendations, glucose utilization, glucose transporters, fatty acids.

\section{INTRODUCTION}

According to the American Heart Association (AHA) Nutrition Committee, "Some popular high-protein/low-carbohydrate diets limit carbohydrates to 10 to $20 \mathrm{~g} / \mathrm{d}$, which is one fifth of the minimum $100 \mathrm{~g} /$ day that is necessary to prevent loss of lean muscle tissue ${ }^{1}$." Clearly, this is an incorrect statement since catabolism of lean body mass is reduced by ketone bodies (possibly through suppression of the activity of the branchedchain 2-oxo acid dehydrogenase), which and probably explains the preservation of lean tissue observed during very-low-carbohydrate diets. Unfortunately, the leading exercise physiology textbook also claims a "lowcarbohydrate diet sets the stage for a significant loss of lean tissue as the body recruits amino acids from muscle to maintain blood glucose via gluconeogenesis ${ }^{2}$." Thus, it is certainly time to set the record straight.

\section{THE KETONE BODIES ARE AN IMPORTANT FUEL}

The hormonal changes associated with a low carbohydrate diet include a reduction in the circulating levels of insulin along with increased levels of glucagon. This activates phosphoenolpyruvate carboxykinase, fructose 1,6-biphosphatase, and glucose 6-phosphatase and also inhibits pyruvate kinase, 6 phosphofructo-1-kinase, and glucokinase. These changes indeed favor gluconeogenesis. 
However, the body limits glucose utilization to reduce the need for gluconeogenesis. In the liver in the well-fed state, acetyl CoA formed during the $\beta$-oxidation of fatty acids is oxidized to $\mathrm{CO}_{2}$ and $\mathrm{H}_{2} \mathrm{O}$ in the citric acid cycle. However, when the rate of mobilization of fatty acids from adipose tissue is accelerated, as, for example, during very low carbohydrate intake, the liver converts acetyl CoA into ketone bodies: Acetoacetate and 3-hydroxybutyrate. The liver cannot utilize ketone bodies because it lacks the mitochondrial enzyme succinyl CoA:3ketoacid CoA transferase required for activation of acetoacetate to acetoacetyl $\mathrm{CoA}^{3}$. Therefore, ketone bodies flow from the liver to extra-hepatic tissues (e.g., brain) for use as a fuel; this spares glucose metabolism via a mechanism similar to the sparing of glucose by oxidation of fatty acids as an alternative fuel. Indeed, the use of ketone bodies replaces most of the glucose required by the brain. Not all amino acid carbon will yield glucose; on average, $1.6 \mathrm{~g}$ of amino acids is required to synthesize $1 \mathrm{~g}$ of glucose ${ }^{4}$. Thus, to keep the brain supplied with glucose at rate of 110 to $120 \mathrm{~g} / \mathrm{day}$, the breakdown of 160 to $200 \mathrm{~g}$ of protein (close to $1 \mathrm{~kg}$ of muscle tissue) would be required. This is clearly undesirable, and the body limits glucose utilization to reduce the need for gluconeogenesis and so spare muscle tissue. In comparison with glucose, the ketone bodies are a very good respiratory fuel. Whereas $100 \mathrm{~g}$ of glucose generates 8.7 $\mathrm{kg}$ of ATP, $100 \mathrm{~g}$ of 3-hydroxybutyrate can yield $10.5 \mathrm{~kg}$ of ATP, and $100 \mathrm{~g}$ of acetoacetate $9.4 \mathrm{~kg}$ of ATP ${ }^{5}$. The brain will use ketone bodies whenever provided with them (i.e., whenever blood ketone body levels rise). The blood-brain barrier transporter for ketone bodies is induced during starvation or very low carbohydrate intake, further promoting the flow of ketone bodies ${ }^{6}$. This transporter has a $K_{\mathrm{m}}$ that exceeds the concentrations of circulating ketone bodies that occur during starvation or very low carbohydrate intake, and a $V_{\max }$ well in excess of energy demands ${ }^{6}$. Therefore, ketone body delivery to brain will never be limited by this transporter. However, continued use of some glucose appears obligatory ${ }^{6}$ and is supplied by way of hepatic gluconeogenesis. Finally, because of the inactivation of pyruvate dehydrogenase (by the low insulin concentration), the glucose that is used by tissues outside the brain is largely only partially broken down to pyruvate and lactate, which can then be recycled in the liver trough gluconeogensis ${ }^{7}$. Therefore, red blood cells, for instance, which have an obligatory requirement for glucose, are not depleting the body of glucose. Interestingly, Volek et al. recently reported that a very-lowcarbohydrate diet resulted in a significant reduction in fat mass and a concomitant increase in lean body mass in normal-weight men ${ }^{8}$. They hypothesized that elevated $\beta$ hydroxybutyrate concentrations may have played a minor role in preventing catabolism of lean tissue but other anabolic hormones were likely involved (e.g., growth hormone).

\section{DIABETIC KETOACIDOSIS VS. DIETARY KETOSIS}

Diabetic patients know that the detection in their urine of the ketone bodies is a danger signal that their diabetes is poorly controlled. Indeed, in severely uncontrolled diabetes, if the ketone bodies are produced in massive supranormal quantities, they are associated with ketoacidosis ${ }^{5}$. In this life-threatening complication of diabetes mellitus, the acids 3hydroxybutyric acid and acetoacetic acid are produced rapidly, causing high concentrations of protons, which overwhelm the body's acidbase buffering system. However, during very low carbohydrate intake, the regulated and controlled production of ketone bodies causes a harmless physiological state known as dietary ketosis. In ketosis, the blood $\mathrm{pH}$ remains buffered within normal limits ${ }^{5}$. Ketone bodies have effects on insulin and glucagon secretions that potentially contribute to the control of the rate of their own formation because of antilipolytic and lipolytic hormones, respectively ${ }^{9}$. Ketones also have a direct inhibitory effect on lipolysis in adipose tissue ${ }^{10}$. 
Interestingly, the effects of ketone body metabolism suggest that mild ketosis may offer therapeutic potential in a variety of different common and rare disease states ${ }^{11}$. The large categories of disease for which ketones may have therapeutic effects are: 1) diseases of substrate insufficiency or insulin resistance; 2) diseases resulting from free radical damage; and 3) disease resulting from hypoxia $^{11}$.

\section{THERE IS NO CLEAR REQUIREMENT FOR DIETARY CARBOHYDRATES FOR HUMAN ADULTS}

Although some studies suggest that preexercise muscle glycogen stores determine capacity for prolonged exercise ${ }^{12}$, there is no clear requirement for dietary carbohydrates for human adults ${ }^{13}$. Current carbohydrate recommendations are based on 1) preventing ketosis, and 2) providing glucose beyond minimal needs. However, it is clear that ketosis is not harmful ${ }^{14-16}$, except in the high levels seen in type 1 diabetes. Also, the need to provide glucose above minimal needs is exactly what has never been demonstrated ${ }^{14}$. Indeed, the National Research Council has not established Recommended Dietary Allowance (RDA) for carbohydrates, probably because the human body can adapt to a carbohydrate-free diet and manufacture the glucose it needs.

Nevertheless, some nutritionists contend that the carbohydrate is an essential nutrient. For example, Mcdonald claimed that healthy, moderately active adults require at least $200 \mathrm{~g}$ of carbohydrate daily to sustain normal brain metabolism and muscle function ${ }^{17}$.

However, the author did not provide any evidence supporting this recommendation. Low-carbohydrate diets have been avoided because of the high-fat nature of the diets and the "predicted" associated hypercholesterolemia. However, serum lipids generally improve with the low-carbohydrate diet, especially the triglyceride and HDL measurements. In sharp contrast, highcarbohydrate diets, which reduce high-density lipoprotein (HDL) cholesterol and raise triglyceride levels, exacerbate the metabolic manifestations of the insulin resistance syndrome ${ }^{18}$. Finally, all fats raise HDL cholesterol. The relative potency of fatty acid classes in raising HDL cholesterol is saturated $>$ monounsaturated $>>$ polyunsaturated ${ }^{19}$. Thus, it is clear that replacement of total fat (of any fatty acid distribution) with carbohydrates results in significant reductions in HDL cholesterol ${ }^{19}$. Indeed, recent studies of carbohydrate intake and its relationship to the development of CHD and type 2 diabetes have been rather revealing, showing that an increase in carbohydrate intake is related to increases in both conditions ${ }^{20}$.

\section{INSULIN IS NOT NEEDED FOR GLUCOSE UPTAKE AND UTILIZATION IN HUMANS}

Contrary to popular belief supported by the leading physiology and biochemistry textbooks, there is sufficient population of glucose transporters in all cell membranes at all times to ensure enough glucose uptake to satisfy the cell's respiration, even in the absence of insulin ${ }^{21}$. Insulin can and does increase the number of these transporters in some cells but glucose uptake is never truly insulin dependent. Even under conditions of extreme ketoacidosis there is no significant membrane barrier to glucose uptake - the block occurs "lower down" in the metabolic pathway where the excess of ketones competitively blocks the metabolites of glucose entering the citric acid cycle. Thus, insulin is not needed for glucose uptake and utilization in $\operatorname{man}^{21}$. In fact, the process appears to be general for all polar (watersoluble) substrates, as transporters are the mechanism by which they are transported across the highly non-polar (lipid) cell membranes. When insulin is administered to people with diabetes who are fasting, blood glucose concentrations falls. It is generally assumed that this is because insulin increases glucose uptake into tissues. However, this is not the case and is just another metabolic legend arising from in vitro rat data. It has been shown that insulin at concentrations that 
are within the normal physiological range lowers blood glucose through inhibiting hepatic glucose production ${ }^{21}$.

\section{FATS BURN IN A CARBOHYDRATE FLAME, RIGHT?}

It has been claimed that carbohydrates serve as a primer for fat catabolism ("fats burn in a carbohydrate flame"). However, as pointed out by Robergs and Roberts ${ }^{22}$, this is an incorrect contention. In skeletal muscle, fat certainly does not burn in a carbohydrate flame, as skeletal muscle does not have sufficient quantities of the enzymes to convert glycolytic intermediates into molecules that can be transported into the mitochondria to supplement citric acid cycle intermediates. Further, the production of acetoacyl CoA, a substrate of ketone body formation, can occur only in the liver and thus does not apply to skeletal muscle metabolism. Human skeletal muscle can oxidize at least seven amino acids: leucine, isoleucine, valine, glutamate, asparagine, aspartate and alanine. Of these amino acids, however, oxidation of only the branched chain amino acids (leucine, isoleucine and valine) appears to be increased during catabolic states such as exercise.
When muscle glycogen and blood glucose concentrations are low, the incorporation of the carbon skeletons from amino acids into the citric acid cycle is important for maintaining the concentrations of the intermediates, and therefore a high rate of mitochondrial respiration. Thus, both muscle fat and carbohydrate burn in an amino acid flame. As discussed by Robergs and Roberts 22 , amino acid catabolism during exercise is important for three reasons: 1) for free energy during exercise to fuel muscle contraction; 2) to increase concentrations of citric acid cycle intermediates and therefore support carbohydrate and lipid catabolism; and 3) to serve as gluconeogenic precursors. It has also been claimed that carbohydrate provides the only macronutrient substrate whose stored energy generates ATP nonaerobically. This is not the case, however, since several studies have shown that amino acid catabolism also provides a source of anaerobic energy production ${ }^{23}$, Aspartate, for example, can be fermented to succinate or propionate $^{24}$. Interestingly, Ivy et al. ${ }^{25}$ and Saunders et al. ${ }^{26}$, reported that the addition of protein to a carbohydrate supplement enhanced endurance performance above that which occurred with carbohydrate alone.

\section{REFERENCES}

1. St. Jeor ST, Howard BV, Prewitt E et al. Dietary protein and weight reduction: A statement for health care professionals from the Nutrition Committee of the Council on Nutrition, Physical Activity, and Metabolism of the American Heart Association. Circulation 2001;104:1869-1874.

2. McArdle WD, Katch FI, Katch VL. Exercise Physiology: Energy, Nutrition and Human Performance. Philadelphia: Lippincott Williams \& Wilkins, 2001.

3. Goodridge AG, Sul HS. Lipid metabolism - Synthesis and oxidation. In: Stipanuk MH, ed. Biochemical and Physiological Aspects of Human Nutrition. Philadelphia, PA: W.B. Saunders Company, 2000, pp. 305-350.

4. Watford M, Goodridge AG. Regulation of fuel utilization. In: Stipanuk MH, ed. Biochemical and Physiological Aspects of Human Nutrition. Philadelphia, PA: W.B. Saunders Company, 2000, pp. 384-407.

5. Salway JG. Metabolism at a Glance. Oxford: Blackwell Science, 1999.

6. Fernstrom JD, Fernstrom MH. Nutrition and the brain. In: Gibney MJ, Macdonald IA, Roche, HM, eds. Nutrition \& Metabolism. Oxford, UK: Blackwell Science, 2003, pp. 145-167.

7. Frayn KN, Akanji AO. Intergration of metabolism 3: Macronutrients. In: Gibney MJ, Macdonald IA, Roche, HM, eds. Nutrition \& Metabolism. Oxford, UK: Blackwell Science, 2003, pp. 74-95.

8. Volek JS, Sharman MJ, Love DM et al. Body composition and hormonal responses to a carbohydrate-restricted diet. Metabolism 2002;51:864-870.

9. Zammit VA. Regulation of ketogenesis in liver: In Handbook of Physiology - Section 7: The Endocrine System - Volume II: The Endocrine Pancreas and Regulation of Metabolism. Oxford: Oxford University Press, 2001, pp. 659-673.

10. Björntorp P. Effect of ketone bodies on lipolysis in adipose tissue in vitro. J Lipid Res 1966;7:621-626.

11. Veech RL. The therapeutic implications of ketone bodies: the effects of ketone bodies in pathological conditions: ketosis, ketogenic diet, redox states, insulin resistance, and mitochondrial metabolism. Prostaglandins Leukot Essent Fatty Acids 2004;70:309-19.

12. Burke LM. Nutrition for training and competition. In: Hargreaves M, Hawley J, eds. Physiological Bases of Sports Performance. Australia: Mc-Graw-Hill Australia, 2003, pp. 152-182.

13. Westman EC. Is dietary carbohydrate essential for human nutrition? Am J Clin Nutr 2002;75:951-954. 
14. Feinman RD, Makowske M. Metabolic syndrome and low-carbohydrate ketogenic diets in the medical school biochemistry curriculum. Metab Synd Relat Disord 2003;1:189-197.

15. Veech RL, Chance B, Kashiwaya Y et al. Ketone bodies: therapeutic uses. IUBMB Life 2001;51:241-247.

16. Sato K, Kashiwaya Y, Keon CA et al. Insulin, ketone bodies, and mitochondrial energy transduction. FASEB J 1995;9:651658.

17. Macdonald IA. Carbohydrate as a nutrient in adults: range of acceptable intakes. Eur J Clin Nutr 1999;53:S101-106.

18. Willett WC. Reduced-carbohydrate diets: no roll in weight management? Ann Intern Med 2004;140:836-837.

19. Ginsberg HN, Karmally W. Nutrition, lipids, and cardiovascular disease. In: Stipanuk MH, ed. Biochemical and Physiological Aspects of Human Nutrition. Philadelphia, PA: W.B. Saunders Company, 2000, pp. 917-944.

20. Aljada A, Mohanty P, Dandona P. Lipids, carbohydrates, and heart disease. Metab Synd and Relat Disord 2003;1:185-188.

21. Sonksen PH. Insulin, growth hormone and sport. J Endocrinol 2001;170:13-25.

22. Robergs RA, Roberts SO. Fundamental Principles of Exercise Physiology for Fitness, Performance, and Health. New York: McGraw-Hill, 2000.

23. Hochachka PW, Dressendorfer RH. Succinate accumulation in man during exercise. Eur J Appl Physiol 1976;35:235-242.

24. Di Pasquale MG. Amino Acids and Proteins for the Athletes: The Anabolic Edge. Boca Raton, FL: CRC Press, 1997

25. Ivy JL, Res PT, Sprague RC, Widzer MO. Effect of a carbohydrate-protein supplement on endurance performance during exercise of varying intensity. Int J Sport Nutr Exerc Metab 2003;13:382-95.

26. Saunders MJ, Kane MD, Todd MK. Effects of a carbohydrate-protein beverage on cycling endurance and muscle damage. Med Sci Sports Exerc 2004;36:1233-8. 